\title{
Soumyabrato Bagchi
}

Public Policy \& Management Group Indian Institute of Management Calcutta Joka, Calcutta 700104

West Bengal, India

Email: soumyabratob13@iimcal.ac.in

Twitter: @bratosoumya

\section{Bangladesh: Reform Agenda for Local Governance by Tofail Ahmed}

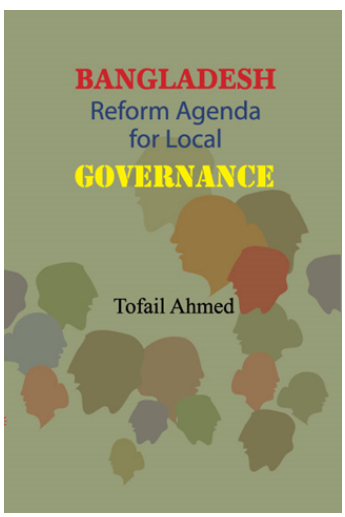

(Prothoma Prokashani, Dhaka, Bangladesh, 2016, ISBN 201601000143, TK 260)

http://bigd.bracu.ac.bd/index.php/resources/booklets/543-bangladeshreform-agenda-for-local-governance-by-tofail-ahmed

The book under review, Bangladesh: Reform Agenda for Local Governance by Tofail Ahmed, is an important contribution to the growing literature on reforms in the area of local governance. The significance of the book lies in its focus on the crisis in local governance, which has become an alarming question in Bangladesh over the last few decades. Ahmed sees several commonalities in independent Bangladesh's local government institutions (LGIs) with that of colonial India since both countries share a common history of local governance. After independence in 1971, articles 11, 59, and 60 of the Constitution of the People's Republic of Bangladesh stipulate a well-defined structure of LGIs. The LGIs in rural areas have a three-tier hierarchical structure made up of union parishad at the village level, upazila parishad at the sub-district level, and zila parishad at the district level, while the urban areas have single-tier LGIs (municipalities or city corporations) depending on the size of the town/ city. Apart from statutory LGIs, three hill districts of the Chittagong Hill Tracts, Rangamati, Khagrachari and Banderban, continue to have a traditional system known as a circle chiefs-headman-karbari system as well as separate district councils.

Ahmed highlights that LGIs in Bangladesh are endowed with a long list of functions, but almost no money and functionaries are provided to fulfil the requirements of local governance. Moreover, regular

DOI: https://doi.org/10.5130/cjlg.v0i21.6519

Article History: Received 14/06/17; Accepted 20/11/18; Published 01/04/2019

Citation: Commonwealth Journal of Local Governance 2018, 21: 6519, - https://doi.org/10.5130/cjlg.v0i21.6519

(C) 2019 Soumyabrato Bagchi. This is an Open Access article distributed under the terms of the Creative Commons Attribution 4.0 Unported (CC BY 4.0) License (https://creativecommons.org/licenses/by/4.0/), allowing third parties to copy and redistribute the material in any medium or format and to remix, transform, and build upon the material for any purpose, even commercially, provided the original work is properly cited and states its license. 
elections are only held at the village and the sub-district level. In parallel with the LGIs, Bangladesh has a complex hierarchal local administrative structure at different levels. Such coexistence often creates dispute between the two sets of institutions. In order to express the complexity of the situation, the author discusses the local administrative structure side by side with the LGIs. Ahmed indicates that this local administrative structure is made up of fragmented agencies such as a general purpose administration or an apex body, regulatory departments, development departments, and service providing agencies. The government officials are vertically aligned with their parent department and ministries, but hardly any horizontal linkages and accountability mechanisms exist at each level with their corresponding local government institutions. Some ad hoc coordination among government departments through a committee system is taken up, but Ahmed asserts that in reality such committees became non-functional 'gossip shops'. Ahmed makes an important observation on the viability of the LGIs; he believes that the achievement of their goals will remain unattainable if a network of cooperation is not adopted. In addition, in terms of local service delivery, Ahmed observes that LGIs are bestowed with service obligations but with unfunded mandates, whereas parallel service agencies are allocated with funds and functionaries to provide the same services. Hence, he advocates the necessity of service agencies and local government representatives working together to develop local service plans.

Bangladesh is one of the signatories of the Cardiff Consensus, an agenda for Commonwealth member countries for local economic development (LED). It emphasises formal planning for LED, where local governments in partnership with other stakeholders play an important facilitating role. In this context, Ahmed shows his dissatisfaction with the national budgetary process, national plan documents such as the annual development plans, the five-year development plans and Perspective Plan 2010-2020, none of which, he believes, address the issue with clarity. The book highlights the need to tie up the national development plan with local development plans to encourage effective growth with local participation.

Ahmed reflects on the country's recent engagement with four major policy documents, including Vision 2021, the election manifesto of Bangladesh Awami League before the ninth parliamentary election (2008), the Perspective Plan 2010-2020, and the Sixth Five-Year Plan (FYP) (2011-2015). This section of the book attempts to focus on the role of LGIs, field administration, local service delivery, local economic development, and local democracy as outlined in the policy documents for establishing a participatory development environment and good governance. Here, Ahmed neatly shows the way LGIs were neglected in the Perspective Plan (2010-2020) and the Sixth FYP (2011-2015). Ahmed proposes a separate chapter for the LGIs in the Seventh FYP to addresses the issues of the local level plans, budget, service delivery and LED. 
In an important section in the book on reforms for the LGIs, Ahmed focuses our attention in great detail on the fact that LGIs in Bangladesh do not operate under a general and composite governance system. Rather it contains a group of different units formed under separate laws, functioning independently, and having similar obligations. Different tiers and units of LGIs follow separate laws, rules, and electoral systems for conducting elections in their respective tiers and units. As a result, it becomes expensive to hold elections, and ambiguity in the system creates a lack of cooperation among elected candidates. A large number of elected candidates become inactive after election, and high-quality candidates lose their interest in joining politics. All these, Ahmed argues, have led to a disorganised organisational structure, perplexing central-local and local-local relationships, giving rise to a strong bureaucracy over elected bodies. Ahmed proposes a reform in the electoral system for both rural and urban areas, and suggests a 'mayor in council' system for the LGIs where mayors or chairs will head an executive council (EC), but not be sole decision makers. Ahmed advocates there should be at least five other members in the EC, including speakers, a leader of the house, deputy leader of the house, and leader of the opposition. A constitutional safeguard like the 1993 73rd and 74th Amendment of the Indian Constitution might be required in order to provide a clear function and mandate to the LGIs. Ahmed also expresses his disappointment on planning in LGIs. He argues that LGIs should not be allowed to disburse resources without a proper annual plan or FYP, with the National Planning Commission, Bangladesh Bureau of Statistics, and local offices assisting LGIs to prepare plans at the local level.

Various tiers and units of LGIs in the country suffer from a scarcity of adequate and efficient manpower. Ahmed discusses measures to counteract this, such as the compilation of 17 departments at sub-district level and 13 offices at village level, including the replacement of the community police with a town police system. Also, the LGIs in Bangladesh have only partial success in women's political and social empowerment in spite of one-third seats reserved on the council for women. It is often argued that women elected members have less power when compared with their male counterparts. To combat this, Ahmed suggests adopting a rotational electoral system as followed in India.

While Ahmed's arguments are mostly backed by extensive research and his primary knowledge in policy advocacy, the author sometimes leaves out a few areas of reform in public management, and its relationship with politics at the grassroots. He does not, for instance, show how decisions are taken at LGIs and to what extent local voices get reflected in policy making, and the politics of such decisions. While he does talk in detail about the various tiers, the author somehow excludes the role of ward sabha, an important forum that can act as a decision-making body of voters in an area, although he has published an article on this in issue 19 of this journal. These are minor issues and there is no doubt that this book is a useful addition to the literature on reform agenda for local governance. Ahmed's research 
provides a roadmap for future reform in Bangladesh in line with the Cardiff Consensus and Vision 2021. The book will also encourage future research and is essential reading for those interested in understanding the crisis in contemporary LGIs in Bangladesh, and the possible reforms required to address this crisis.

\section{Declaration of conflicting interest}

The author declared no potential conflicts of interest with respect to the research, authorship, and/or publication of this article.

\section{Funding}

The author received no financial support for the research, authorship, and/or publication of this article. 